\section{Incident Open-Angle Glaucoma and Ocular Perfusion Pressure}

The purpose of this letter is to provide corrections to a recent paper from the Rotterdam Eye Study, ${ }^{1}$ which evaluated the relationship between incident open-angle glaucoma (OAG) and ocular perfusion pressure (OPP). After adjustment for intraocular pressure (IOP), the researchers failed to find significant associations with OPP, concluding that the positive results of previous reports may be due to nonadjustment for IOP. Supporting this premise, the Discussion section noted that studies with adjustment for IOP also had nonsignificant associations with mean OPP, including the Barbados Eye Study and the Early Manifest Glaucoma Trial.

This statement on the Barbados data is incorrect, as it is based on analyses that were not adjusted for IOP and did not evaluate mean OPP; those analyses, based on OAG prevalence, yielded significant associations with diastolic OPP. ${ }^{2}$ Subsequent Barbados reports, in which data were adjusted for IOP and were based on 4- and 9-year incidences, ${ }^{3,4}$ seem most relevant to the Rotterdam incidence results, but were not mentioned. These reports on the Barbados incidence data documented strong associations with systolic, diastolic, and mean OPP ${ }^{3,4}$ both before and after IOP adjustment. As an additional clarification, the IOP-adjusted analyses from the Early Manifest Glaucoma Trial revealed significant relationships between OAG progression and systolic OPP. ${ }^{5}$ The results of those longitudinal studies, therefore, are not consistent with the Rotterdam report.

In addition to their diverse populations and research designs, differences in OPP results among studies could be due to many reasons (e.g., the Rotterdam OAG criteria were based only on visual field defects, while the Barbados criteria required both field defects and disc damage). Furthermore, we have an incomplete understanding of vascular factors in OAG and how to best evaluate the role of OPP. ${ }^{6}$ The investigations conducted by the Rotterdam Study were thorough. However, given the oversights noted and the complexity of OPP assess- ment, ${ }^{6}$ it seems prudent to temper their conclusion that the link between OPP and OAG reported by others may be an "artifact" from lack of IOP adjustment.

$$
\begin{aligned}
& \text { M. Cristina Leske }{ }^{1,2} \\
& \text { Sub-Yub Wu } \text { W }^{1,2} \\
& \text { Barbara Nemesure }^{1,2} \\
& \text { Anselm Hennis }^{1,3,4}
\end{aligned}
$$

Departments of ${ }^{1}$ Preventive Medicine and ${ }^{2}$ Ophthalmology, Stony Brook University, Stony Brook, New York; the ${ }^{3}$ Ministry of Health, Barbados, West Indies; and the ${ }^{4}$ Chronic Disease Research Centre, Tropical Medicine Research Institute, University of the West Indies, Barbados, West Indies.

E-mail: cleske@notes.cc.sunysb.edu

Supported by Grants EY07625 and EY07617 from the National Eye Institute, Bethesda, Maryland.

\section{References}

1. Ramdas WD, Wolfs RCW, Hofman A et al. Ocular perfusion pressure and the incidence of glaucoma: real effect or artifact?-The Rotterdam Study. Invest Ophthalmol Vis Sci. 2011;52:6875-6881.

2. Leske MC, Connell AMS, Wu SY, Hyman L, Schachat AP and the Barbados Eye Study Group. Risk factors for open-angle glaucoma: The Barbados Eye Study. Arch Ophthalmol. 1995;113:918-924.

3. Leske MC, Wu SY, Nemesure BN, Hennis A, for the Barbados Eye Studies Group. Incident open-angle glaucoma and blood pressure. Arch Ophthalmol. 2002;120:954-959.

4. Leske MC, Wu S-Y, Hennis A, Honkanen R, Nemesure B, BESs Study Group. Risk factors for incident open-angle glaucoma: The Barbados Eye Studies. Ophthalmology. 2008;115(1):85-93.

5. Leske MC, Heijl A, Hyman L, Bengtsson B, Dong L, Yang Z, EMGT Group. Predictors of long-term progression in the Early Manifest Glaucoma Trial. Ophthalmology. 2007;114(11):1965-1972.

6. Leske MC. Ocular perfusion pressure and glaucoma: clinical trial and epidemiologic findings. Curr Opin Ophthalmol. 2009;20:73-78.

Citation: Invest Ophthalmol Vis Sci. 2011;52:7943.

doi:10.1167/iovs.11-8394 